Fetal Diagnosis and Therapy

\title{
Update on the Diagnosis and Prognosis of Preeclampsia with the Aid of the sFIt-1/ PIGF Ratio in Singleton Pregnancies
}

\author{
Ignacio Herraiz ${ }^{a}$ Elisa Llurba ${ }^{b}$ Stefan Verlohren ${ }^{c}$ Alberto Galindo ${ }^{a}$ on behalf \\ of the Spanish Group for the Study of Angiogenic Markers in Preeclampsia \\ ${ }^{a}$ Fetal Medicine Unit, Maternal and Child Health and Development Network (SAMID-RD12/0026/0016), Instituto \\ de Investigación Sanitaria Hospital 12 de Octubre (imas12), Department of Obstetrics and Gynecology, Hospital \\ Universitario 12 de Octubre, Universidad Complutense de Madrid, Madrid, and bepartment of Obstetrics \\ and Gynecology, Maternal and Child Health and Development Network (SAMID-RD12/0026/0016), Sant Pau \\ University Hospital, Universidad Autónoma de Barcelona, Barcelona, Spain; 'Department of Obstetrics, Charité \\ Universitätsmedizin Berlin, Berlin, Germany
}

\section{Keywords}

Placental dysfunction · Preeclampsia - Angiogenesis . sFIt-1/PIGF ratio

\begin{abstract}
Preeclampsia (PE) is involved in a group of obstetrical conditions closely related by the presence of placental dysfunction (PD), which also includes intrauterine growth restriction and placental abruption. The timely and accurate recognition and management of PE are often challenging because diagnostic criteria are still based on nonspecific signs and symptoms and because common severity criteria correlate poorly with adverse maternal and fetal outcomes. The discovery of the role of angiogenesis-related factors - soluble fms-like tyrosine kinase-1 (sFlt-1) and placental growth factor (PIGF) - in the underlying pathophysiology of PD has marked an important step for improving its early diagnosis and prognosis assessment before gestational week 34. Nowadays, an sFlt-1/PIGF ratio cutoff level of $\leq 38$ is widely accepted for ruling out PE in patients with suspicion of the disease, and its use is cost-effective. However, the evidence is
\end{abstract}

\section{KARGER}

(c) 2017 S. Karger AG, Basel

E-Mail karger@karger.com

www.karger.com/fdt more limited regarding the management and prognosis of women with an abnormally high sFlt-1/PIGF ratio. This review summarizes the current evidence of the clinical application of the sFlt-1/PIGF ratio for the diagnosis and prognosis assessment of $\mathrm{PE}$ and points out the next challenges for these biomarkers, including their role as target for the development and monitoring of new therapies.

(c) 2017 S. Karger AG, Basel

\section{Brief Overview of the Current Understanding of Preeclampsia Based on Angiogenic Markers}

Placental dysfunction (PD) underlies a spectrum of conditions, namely preeclampsia $(\mathrm{PE})$, intrauterine growth restriction (IUGR), and placental abruption (PA), and constitutes a major cause of fetal and maternal morbidity and mortality [1]. Although the underlying origin of PD is still unknown, PD is characterized by defective deep trophoblastic invasion and impaired maternal spiral artery remodeling in the first half of pregnancy, subsequently leading to inadequate placental perfusion. Re- 
duced remodeling of the spiral arteries in their myometrial segments precludes the proper regulation of flow pressure to the intervillous space, causing villous damage and an impairment of the materno-fetal exchange leading to IUGR [2]. This shallow implantation can also favor placental detachment leading to acute or chronic PA.

Today it is known that PD triggers an imbalance in the maternal circulation of angiogenesis regulatory factors characterized by, firstly, elevated concentrations of antiangiogenic factors released by the dysfunctional hypoxic placenta, such as soluble fms-like tyrosine kinase-1 (sFlt-1). sFlt-1 is responsible for the maternal dysfunction, causing peripheral vasoconstriction in an attempt to raise maternal blood pressure. This is intended to increase the oxygenated maternal blood flow through the intervillous space, but eventually can lead to a systemic vascular disorder named PE [3]. Secondly, the bioavailability of free proangiogenic factors, such as vascular endothelial growth factor and placental growth factor (PlGF), is markedly decreased since they are captured and inhibited by sFlt-1. These are key factors for the normal growth of new blood vessels as well as for the proliferation, survival, and fenestration of endothelial cells [4]. Their imbalance is directly involved in the clinical manifestations associated with PE [5], especially in the most severe and early-onset forms, and is already present more than 1 month before the first clinical symptoms appear [6].

Notwithstanding, this antiangiogenic state does not always result in the development of the maternal syndrome of PE. The reasons for this are still unclear, but it is possible that PE develops clinically once an individual threshold of angiogenic imbalance is reached. A combination of sufficiently severe and prolonged endothelial insult, together with a constitutional maternal predisposition, is probably required. Thus, the most seriously defective placentation causes placental syncytial stress from early stages of pregnancy, with the subsequent release of extremely high amounts of sFlt-1 by the syncytiotrophoblast, leading to early-onset PD in virtually all cases. Furthermore, the greater the maternal sensitivity to endothelial damage, the earlier and more severe the PD. On this part of the spectrum, the coexistence of PE and IUGR is common [7]. PA, although a rare event, also shows an association along with preceding alterations in angiogenesis-related biomarkers [8], and very high sFlt-1/PlGF ratios have been described shortly before the onset of PA $[9,10]$. Lesser degrees of placental damage (which may not be caused by a defective placental invasion, but subsequent alterations in placental perfusion or oxidative stress) [11] might generate enough antiangiogenic insult to give rise to variable forms of $\mathrm{PD}$, both regarding the time of presentation and severity, depending on the maternal constitution. Finally, late-onset PD is more commonly associated with less or no placental damage and usually appears in women with long-term cardiovascular risk factors, such as chronic hypertension, renal disease, thrombophilia, diabetes and obesity, in whom even the physiological changes at the end of pregnancy can induce endothelial dysfunction leading to PE [12]. Late-onset PE usually presents with adequate or large for gestational age fetuses, low rates of severe complications, and normal angiogenic profile, although there is a subtype of late-onset PE with altered angiogenic profile that is more prone to IUGR [13] and adverse outcomes [14]. On the other hand, a certain degree of placental stress can be found as the upper limit of the capacity of the uteroplacental circulation is reached in the final stages of pregnancy. Thus, in late pregnancy, the limits between normal and dysfunctional placenta are blurred, as is the ability of the biomarkers of $\mathrm{PD}$ to differentiate between pathological and normal pregnancy [15].

Therefore, there are probably several entities currently included under the concept of PE and other PD-related disorders, but whose prognosis and onset are different depending on their underlying relation to placental damage, angiogenic state, and maternal susceptibility.

Despite these advances, our ability to manage PD-related diseases has not improved accordingly. As a paradigm, the diagnosis of PE still relies on the demonstration of new-onset hypertension and proteinuria in the second half of pregnancy, although their presence does not always precedes the onset of complications and has no ability to predict PE-related adverse outcomes [16]. These limitations may lead to the recognition of PE in an advanced stage of the disease, hindering its early diagnosis as well as its optimal management and potentially leading to severe fetal and maternal complications. That is why current efforts are focused on expanding the definition of $\mathrm{PE}$ to recognize its multisystem nature [17] as well as implementing strategies in the clinical setting based on the use of in vitro diagnostic tests for PD, such as the sFlt-1/ PlGF ratio, in order to improve the prediction, diagnosis, and prognosis assessment of $\mathrm{PD}$, especially $\mathrm{PE}$, and thereby improving maternal and fetal outcomes. This review will focus on the use of angiogenic markers for the diagnosis and prognosis of PD. However, it should not be forgotten that it is more than likely that in the near future these markers will also play a fundamental role in the prediction of PD in the first trimester [18]. 


\section{Clinical Implementation of Angiogenic Markers in the Second Half of Pregnancy}

\section{Aid in the Suspicion and Diagnosis of PE}

It has been demonstrated that the main modifiable prognostic factor for avoiding complications related to PD is the optimization of antenatal care. This becomes evident when it is noticed that fetal and maternal morbidity and mortality related to $\mathrm{PE}$ are much greater in underresourced countries because of restricted access to appropriate health services. In the developed world, the morbidity and mortality of $\mathrm{PE}$ arise from two main causes: (1) lack of specific and sensible methods for its diagnosis and prognosis, and (2) the fact that the presentation and the course of the disease are often unpredictable. Most PE-related deaths are avoidable and due to substandard care. In the latest UK Report of the Confidential Enquiries into Maternal Deaths (the CMACE report) [19], in 20 out of the 22 deaths related to $\mathrm{PE}$ the patients received substandard care, a disturbing number that is higher than for any other cause of maternal death. Moreover, the majority of adverse outcomes occurred in women not fulfilling the classical definition of PE [17] or not having risk factors [20]. Therefore, early estimation of patient-specific risks for these pregnancy complications could potentially improve outcome by means of referring such patients to specialized centers, close monitoring, targeted interventions, and timely delivery [21].

On the other hand, a great proportion of women with suggestive symptoms and/or signs will not develop any complication of pregnancy, but they are often hospitalized until PE and related adverse outcomes are ruled out [22]. Certainly, caring for women who present with elevated blood pressure in the second half of pregnancy can be extremely challenging. This presentation may reflect gestational hypertension, previously undiagnosed chronic hypertension (that may go unnoticed early in pregnancy when blood pressure typically falls), or PE. Whereas women with gestational hypertension and chronic hypertension usually have good pregnancy outcomes, PE requires careful inpatient monitoring for both the mother and the fetus, and possibly early delivery to reduce adverse outcomes. Given the uncertainty and the serious maternal and fetal risks associated with $\mathrm{PE}$, women presenting with hypertension beyond the 20th week of pregnancy undergo standard evaluation and monitoring that usually implies substantial costs derived from hospitalization, laboratory analysis, and fetal wellbeing tests.

The sFlt-1/PlGF ratio has been shown to be useful for establishing the real risk of developing $\mathrm{PE}$ among patients

Update on the Diagnosis and Prognosis of Preeclampsia presenting with clinical suspicion of PE. The recent prospective, multicenter, observational PROGNOSIS study [23] evaluated whether the sFlt-1/PlGF ratio is predictive of the short-term absence or presence of PE in women with suspicion of PE between 24 and $36^{+6}$ weeks of pregnancy: an sFlt- $1 / \mathrm{PlGF}$ ratio $\leq 38$ had a negative predictive value (NPV) (that is, no PE diagnosis) in the subsequent week of 99.3\% (95\% confidence interval [CI], 97.9-99.9). This NPV remained high at 2 (97.9\%), 3 (95.7\%), and 4 weeks (94.3\%) after testing [24], whereas the positive predictive value (PPV) of an sFlt-1/PlGF ratio $>38$ to rule in PE within the next 4 weeks was $36.7 \%$ (95\% CI, 28.445.7 ), with $66.2 \%$ sensitivity (95\% CI, 54.0-77.0) and $83.1 \%$ specificity (95\% CI, 79.4-86.3). The same study showed that none of the markers taken individually improved the results of the sFlt-1/PlGF ratio [23]. However, the PELICAN study showed that the PlGF test alone had a very high accuracy for predicting PE needing delivery within 14 days for women presenting with PE suspicion between 20 and 34 weeks of gestation. For a test cutoff $<100 \mathrm{pg} / \mathrm{mL}$, PlGF alone showed $96 \%$ sensitivity (95\% CI, 89-99), 56\% specificity (95\% CI, 49-63), 44\% PPV (95\% CI, 36-52), and 98\% NPV (95\% CI, 93-100) [25]. Therefore, PlGF represents a reasonable alternative to the sFlt-1/PlGF ratio, at least for ruling out $\mathrm{PE}$ at or before 34 weeks. However, the availability of the test used in this study (Triage ${ }^{\circledR}$ PlGF test) is limited and, in addition, the normal reference values of PlGF obtained with one platform may not be interchangeable with others.

The sFlt-1/PlGF ratio has also been shown to be useful for establishing an accurate diagnosis of $\mathrm{PE}$ at a cutoff $>85$ for early-onset PE and $>110$ for late-onset PE, with a very high specificity of $99.5 \%$ (95\% CI, 97.7-100) and 95.5\% (95\% CI, 92.9-100), respectively [26]. Moreover, before 34 weeks, the sFlt-1/PlGF ratio does not increase significantly in pregnant women with chronic hypertension or gestational hypertension compared to normotensive pregnant women, remaining below the cutoff of 85 in $95 \%$ of pregnant women with hypertensive conditions without PE. At $\geq 34$ weeks, a significant increase in the sFlt-1/PlGF ratio is observed in hypertensive pregnant women without $\mathrm{PE}$, but only in a minority of cases $(<10 \%)$ values $>110$ are reached. These data show that the sFlt-1/PlGF ratio is particularly useful for the differential diagnosis of the various hypertensive disorders of pregnancy, especially before 34 weeks [27]. However, some caution is advocated since these data were extracted from studies conducted on selected populations of singleton pregnancies without congenital anomalies. Furthermore, it must be taken into account that angio- 
genesis-related biomarkers provide surrogate information about placental function, so that other PD-related disorders, and IUGR in particular, increase the sFlt-1/ PlGF ratio to values that can frequently exceed the cutoff points for PE suspicion and diagnosis mentioned above [13]. Currently, there is insufficient evidence to establish specific cutoffs for the prediction and diagnosis of IUGR as well as for the distinction between IUGR and PE. Finally, the performance of these markers has not been sufficiently studied in special situations, such as multiple gestations or pregnancies affected by congenital infections, chromosomal abnormalities, or cardiac malformations, in which the results may have a more complex interpretation.

\section{Aid in Management and Prognosis}

Once the diagnosis of $\mathrm{PE}$ is established and expectant management is considered, the angiogenesis-related biomarkers can also provide valuable information, as a surrogate of $\mathrm{PD}$, for guiding the management and assessing the prognosis. A more challenging question is whether a given value of these biomarkers may be used to make clinical decisions, such as the indication of delivery. Until new evidence from randomized clinical trials will clarify this point, the results of the sFlt-1/PlGF ratio must be used in combination with the standard clinical assessment and current guidelines, although they are likely to be useful for a more accurate interpretation of the clinical situation.

After the diagnosis of $\mathrm{PE}$, the next decision to make is determining the most suitable time to end the pregnancy, balancing the benefits for the fetus of continuing pregnancy against the increasing life-threatening risks to the mother as pregnancy progresses. Expectant management is advocated for early-onset $\mathrm{PE}$, as long as fetal viability has been reasonably achieved ( $\geq 24$ weeks of gestation) and maternal and fetal conditions do not suggest imminent major complications. Pregnancy prolongation in this context has been demonstrated to decrease serious perinatal morbidity, since every single day of intrauterine life gained may improve the outcome of the newborn. In an adequate hospital environment and in expert hands for the selection and management of eligible cases, pregnancy prolongation of about 7 days on average is achievable with few serious maternal complications [28]. However, the disturbing difficulty in predicting the course of PE makes some clinicians hesitant to practice expectant management. In an attempt to overcome this problem, the Pre-eclampsia Integrated Estimate of Risk (PIERS) initiative has developed an open-access risk calculator of adverse maternal outcomes (available at https://preempt.cfri.ca/monitoring/fullpiers). This prediction model combines gestational age at eligibility, clinical signs, and laboratory parameters (oxygen saturation, platelet count, and creatinine and aspartate transaminase concentrations) [29]. Although a step forward, this model is still far from ideal, since it only provides robust information for the first $48 \mathrm{~h}$ after admission, gives no information regarding fetal outcome, and widely lacks external validation. Being aware of these limitations as well as of the potential of the angiogenesis-related biomarkers, the PIERS study group has now the goal of integrating PlGF into the model.

Therefore, new prognostic tools are necessary to better identify cases in whom safe prolongation of pregnancy may be attempted. It has been demonstrated that in the subgroup of $\mathrm{PE}$ in which the sFlt-1/PlGF ratio remains normal (the so-called "nonangiogenic PE"), the risk of adverse outcomes is very low [14]. In these cases, clinicians are reassured that a complication in the short term is unlikely, and therefore iatrogenic preterm deliveries for confusing prognostic features, such as the occurrence of occasional headache, or when a certain level of proteinuria is exceeded may be avoided.

On the contrary, very high sFlt-1/PlGF ratios [27] as well as their rapid increase in serial measurements [30, 31 ] are closely related with the imminent onset of PDrelated complications, and this tool has the unique property of being inversely correlated with the time remaining until delivery is indicated. Before 34 weeks (when objective parameters such as the sFlt-1/PlGF ratio may be of greatest interest for guiding management), it was shown that when the sFlt-1/PlGF ratio was $>38$, the remaining time to delivery was $38 \%$ shorter than in women with an sFlt-1/PlGF ratio of $\leq 38$ [32]. If the value was $>85$, delivery occurred within 2 weeks in $86.0 \%$, compared with $15.8 \%$ of women with values $<85(p>0.001)$ [33]. If the sFlt-1/PlGF ratio was $>655$, only 29.4 and $5.9 \%$ of cases lasted more than 2 and 7 days, respectively (versus 50 and $30.8 \%$ when the value was $\leq 655$ ) [27]. Between $34^{+0}$ and $36^{+6}$ weeks of pregnancy, there is still some interest in continuing pregnancy for women with nonsevere PE to achieve better perinatal outcomes [34]. In this gestational phase, an sFlt-1/PlGF ratio $>201$ is considered very high, with only 16.7 and $0 \%$ of patients remaining pregnant after 2 and 7 days, respectively [27]. There is an ongoing clinical trial (NCT02373839) to determine whether induction of delivery in this gestational period is better determined, in terms of perinatal outcomes, by the presence of severity criteria or by abnormal 
values of angiogenesis-related biomarkers. In term pregnancies, there are no apparent benefits of prolonging the pregnancy [35], and therefore biomarkers have less clinical utility.

Interestingly, some case reports have shown that in the exceptional cases of PE in whom placental function improves and symptoms wear off - paradigmatically in mirror syndrome with fetal hydrops of reversible etiology the initially elevated sFlt-1/PIGF ratio returns to normal values $[36,37]$. These dynamic variations according to the clinical situation are not so obvious for other classical features of PE, such as uterine artery Doppler, uric acid, liver enzymes, creatinine, or even blood pressure and proteinuria $[16,22,33]$. However, a limitation when facing abnormal sFlt-1/PlGF ratios is that they are not informative regarding the type of complication that will develop, since different adverse outcomes, such as HELLP syndrome, PA, acute renal failure, pulmonary edema, refractory hypertension, or fetal wellbeing impairment, show similar antiangiogenic states [9]. Therefore, detailed maternal and fetal evaluations are again essential to complete the surveillance.

Despite this amount of data, many obstetricians are still skeptical about the use of biomarkers for the evaluation of PD-related disorders, taking into account that there are no available treatments able to significantly modify the natural history other than delivery. Instead, the sFlt-1/PlGF ratio provides clinicians an objective test of simple interpretation to evaluate PE that may optimize medical care, which is the only modifiable prognostic factor for this disease. Recently, the Preeclampsia Open Study (PreOS) has been the first prospective noninterventional study designed to evaluate the influence of the sFlt-1/PlGF ratio on clinical decision-making in women with suspected PE, with regard to subsequent care [38]. PreOS analyzed the proportion of changes of clinical decisions after knowing the result of the sFlt-1/PlGF ratio. The most common changed decision was regarding monitoring intensity within 1 week, which was revised in $27.2 \%$ of cases, followed by the attitude towards hospitalization $(16.9 \%$,$) and physicians' decisions related to fetal$ maturation (7.7\%). Only in a minority of cases $(1.7 \%$, all cases of late presentation) did the care providers dare to induce delivery after interpretation of the test result. Of note, an independent experts' committee considered all revised decisions appropriate. Further studies are necessary to confirm whether use of the sFlt-1/PlGF ratio is able to improve perinatal results without increasing adverse maternal outcomes.

Update on the Diagnosis and Prognosis of Preeclampsia
Aid in Monitoring the Effect of New Therapies

Next to its use as a predictive and diagnostic marker, the sFlt-1/PlGF ratio is gaining importance as a target for therapies. The group of Thadhani [39] has developed an intervention based on the concept that in $\mathrm{PE}$, excessive placental sFlt-1 is secreted in the maternal circulation and damages the maternal endothelium, causing various aspects of the clinical syndrome [5]. They hypothesized that when the causative agent sFlt- 1 is removed, features of the clinical syndrome must ameliorate [39]. In a pilot study, they were able to show that when removing sFlt-1 with dextran sulfate apheresis, a procedure that is applied in pregnant women for other causes such as hyperlipidemia and is thus safe to use in pregnancy, the pregnancy of the treated patients was prolonged [39]. In a larger study, they confirmed the safety as well as the efficacy of the treatment [40]. As a next step, randomized controlled trials must follow to confirm these results.

A reduction in sFlt- 1 levels is also the rationale behind another experimental treatment for PE: pravastatin. Brownfoot et al. [41] showed in an experimental study that pravastatin reduced sFlt- 1 and decreased endothelial dysfunction in cell culture experiments. Moreover, they presented pilot data suggesting that pravastatin can stabilize clinical and biochemical features of preterm PE. Parallel to this basic research, a multicenter randomized controlled trial has been performed to examine the effect of oral pravastatin on serum sFlt-1 levels in women with preterm PE (ISRCTN23410175), and a separate prevention trial (NCT01717586) has also been started, with encouraging preliminary results [42].

sFlt-1 is therefore an apt target for interventional concepts that are or will be explored in clinical studies. sFlt-1 furthermore has abilities of a surrogate parameter of $\mathrm{PE}$ that consequently might be employed as an indicator of disease status and progression. Potentially, interventional trials on targets that do not directly interact with the sFlt-1 pathway might use this parameter to monitor treatment success.

\section{Clinical Decision-Making Based on Angiogenic Biomarkers: Health Economic Implications}

As shown above, there is solid evidence that the sFlt-1/ PlGF ratio is able to rule out as well as predict PE. Since the PROGNOSIS study, it is clear that determining the sFlt-1/PlGF ratio in women at risk for PE can help decide whom to hospitalize and whom to send home. Recently, a group of international researchers published a consen-

Fetal Diagn Ther 2018;43:81-89 
Table 1. Summary of the recommendations for the use of the sFlt-1/PlGF ratio in women with signs and symptoms of PE based on the opinion of experts in the use of angiogenic markers [43]

\begin{tabular}{|c|c|c|c|}
\hline $\begin{array}{l}\text { sFlt-1/PlGF } \\
\text { result }(\mathrm{EP} / \mathrm{LP})\end{array}$ & Interpretation & $\begin{array}{l}\text { Time to delivery } \\
\text { (EP) }\end{array}$ & What should be done? \\
\hline Low: $<38$ & $\begin{array}{l}\text { Rule out PE: } \\
1 \text { week: } \mathrm{NPV} \approx 99 \% \\
4 \text { weeks: } \mathrm{NPV} \approx 95 \%\end{array}$ & Unmodified & $\begin{array}{l}\text { Reassuring the patient } \\
\text { No further determinations are needed unless new } \\
\text { suspicion arises }\end{array}$ \\
\hline $\begin{array}{l}\text { Intermediate: } \\
38-85 / 38-110\end{array}$ & $\begin{array}{l}\text { Rule in PE: } \\
4 \text { weeks: } \mathrm{PPV} \approx 40 \%\end{array}$ & $\begin{array}{l}20 \% \text { remain } \\
\text { pregnant after } \\
1 \text { month }\end{array}$ & $\begin{array}{l}\text { Follow-up visit and retest in } 1-2 \text { weeks } \\
\text { Maternal education about signs and symptoms of PE }\end{array}$ \\
\hline $\begin{array}{l}\text { High: } \\
>85 />110\end{array}$ & $\begin{array}{l}\text { Diagnosis of PE (or PD-related } \\
\text { disorder) is highly likely }\end{array}$ & $\begin{array}{l}15 \% \text { remain } \\
\text { pregnant after } \\
2 \text { weeks }\end{array}$ & $\begin{array}{l}\text { Follow-up visit and retest in } 2-4 \text { days } \\
\text { EP: consider referral to higher-level center } \\
\text { LP: consider lowering the threshold for labor induction }\end{array}$ \\
\hline $\begin{array}{l}\text { Very high: } \\
>655 />201\end{array}$ & $\begin{array}{l}\text { Short-term complications and } \\
\text { need to deliver are highly likely }\end{array}$ & $\begin{array}{l}30 \% \text { remain } \\
\text { pregnant after } \\
2 \text { days }\end{array}$ & $\begin{array}{l}\text { Close surveillance } \\
\text { EP: corticoids to the mother for fetal maturation }\end{array}$ \\
\hline
\end{tabular}

NPV, negative predictive value; PD, placental dysfunction; PE, preeclampsia; PlGF, placental growth factor; PPV, positive predictive value; sFlt-1, soluble fms-like tyrosine kinase-1; EP, early phase ( $<34$ weeks of gestation); LP, late phase ( $\geq 34^{+0}$ weeks of gestation).

sus statement on how to use the sFlt-1/PlGF ratio in clinical practice [43]. The aim was to review the existing evidence on the established cutoffs of 38 (prediction), 85/110 (diagnosis), and putative actions to be taken based on these results (Table 1).

However, the clinical implementation of new medical knowledge is always dependent on local policy and regulations and may vary substantially. On the level of availability, differences exist internationally. The sFlt-1/PlGF ratio is a CE-certified in vitro diagnostic test manufactured by different pharmaceutical companies. It is thus available in all countries accepting the CE mark in Europe, Latin America, Middle East, Africa, and Asia. It is not available in the United States as the Food and Drug Association (FDA) has not approved it yet. Also in Japan approval is pending. On the level of health care guidance bodies, substantial differences exist between European countries. For the UK, the National Institute for Health and Care Excellence (NICE) has recognized the ability of the sFlt-1/PlGF ratio to rule out PE for women presenting with suspected PE between 20 and 34 weeks of gestation. In its recently published guideline, NICE declares that the test "can be used in the NHS to help doctors decide that they do not have preeclampsia" [44]. In Germany, the guidelines of the German Gynecological Society stated already in 2013 that angiogenic factors, namely the sFlt-1/ PlGF ratio, can be used in addition to standard clinical tests to rule in and/or rule out PE in women presenting with signs and symptoms of the disease [45]. Currently, the German guidelines are under revision, and new evidence such as PROGNOSIS will be reflected. Just recently, the Italian Advisory Board recognized that determining the sFlt-1/PlGF ratio is useful to rule out the disease as well as to evaluate the need for hospitalization in patients presenting with signs and symptoms for the disease in tertiary care centers. Furthermore, the use of the sFlt-1/ PlGF ratio to monitor disease severity and to predict maternal and fetal adverse outcomes is suggested for the Italian system [46]. Hopefully more and more national societies will continue incorporating biomarkers in PE guidelines in upcoming years.

On the level of health economic considerations, the potential of the sFlt-1/PlGF ratio to save health care costs has been repeatedly shown. Hadker et al. [47] showed already in 2010 that implementing the sFlt-1/PlGF ratio in the diagnostic workup for patients presenting with signs and symptoms for PE saves health care costs. For the German system, their model estimated that using the sFlt-1/ PlGF ratio, a net saving of EUR 637 per pregnant woman is achieved. The savings are attributed to the test's ability to better classify patients relative to current practice, specifically its ability to reduce false negatives by $67 \%$ and false positives by $71 \%$. For the United States, Schnettler et al. [48] estimated average cost savings of USD 1,215, also mainly by increasing the specificity of $\mathrm{PE}$ diagnosis. They showed that using the sFlt-1/PlGF ratio, the proportion 
of women falsely labeled as "preeclamptic" decreased from $42.3 \%$ (95\% CI, 34.4-50.2\%) to $4.0 \%$ (95\% CI, $0.85-$ $7.15 \%)$, the proportion correctly labeled increased from $23.5 \%$ (95\% CI, $16.7-30.3 \%$ ) to $61.7 \%$ (95\% CI, 53.9$69.5 \%$ ), and a total of $47.2 \%$ of antenatal admissions would potentially be avoided. Recently, Vatish et al. [49] showed from a UK Health Service payer's perspective that implementing the sFlt-1/PlGF ratio into current diagnostic algorithms versus not using this additional information results in cost savings. Applying the test in clinical practice is able to save GBP 344 per patient. Economic modeling showed again that savings are generated primarily through an improvement in diagnostic accuracy and subsequent reduction in unnecessary hospitalizations.

In summary, the sFlt-1/PlGF ratio has been shown to have a strong predictive and diagnostic value for PD-related disorders, and specifically for PE. Moreover, its implementation saves costs. This is of paramount importance for this condition since it has enormous maternal and fetal impact and its diagnosis still relies on nonspecific criteria, which moreover are of late onset in the development of the disease. The sFlt-1/PIGF ratio is here to stay, and in upcoming years we will see it become incor- porated into more and more clinical protocols guiding the diagnosis and management of PE, and hopefully it will be included among the criteria to diagnose PD of clinical importance with a need of follow-up, especially the more severe and/or early forms.

\section{Appendix}

Collaborators of the Spanish Group for the Study of Angiogenic Markers in Preeclampsia: J.L. Bartha, M. de la Calle (Department of Obstetrics and Gynecology, Hospital Universitario La Paz, Universidad Autónoma de Madrid, Madrid, Spain); J.L. Delgado, C. de Paco (Universidad de Murcia and IMIB-Arrixaca, Murcia, Spain); A.I. Escudero, F. Moreno (Department of Obstetrics and Gynecology, Hospital Universitario Central de Asturias, Universidad de Oviedo, Asturias, Spain); J.A. García-Hernández, A. Romero-Requejo (Department of Obstetrics and Gynecology, Hospital Universitario y Politécnico "La Fe," Universidad de Valencia, Valencia, Spain); B. Marcos-Puig, A. Perales (Department of Obstetrics and Gynecology, Hospital Universitario Materno Infantil de Canarias, Universidad de Las Palmas de Gran Canaria, Las Palmas, Spain); M. Mendoza (Maternal-Fetal Medicine Unit, Department of Obstetrics, Maternal and Child Health and Development Network [SAMID-RD12/0026/0016], Hospital Universitario Vall d'Hebrón, Universidad Autónoma de Barcelona, Barcelona, Spain).

\section{References}

1 Friedman AM, Cleary KL: Prediction and prevention of ischemic placental disease. Semin Perinatol 2014;38:177-182.

2 Burton GJ, Woods AW, Jauniaux E, Kingdom JC: Rheological and physiological consequences of conversion of the maternal spiral arteries for uteroplacental blood flow during human pregnancy. Placenta 2009;30:473482.

3 Roberts JM: Pathophysiology of ischemic placental disease. Semin Perinatol 2014;38:139145.

4 Hagmann H, Thadhani R, Benzing T, Karumanchi SA, Stepan H: The promise of angiogenic markers for the early diagnosis and prediction of preeclampsia. Clin Chem 2012;58: 837-845.

5 Maynard SE, Min JY, Merchan J, Lim KH, Li J, Mondal S, Libermann TA, Morgan JP, Sellke FW, Stillman IE, Epstein FH, Sukhatme VP, Karumanchi SA: Excess placental soluble fms-like tyrosine kinase 1 (sFlt1) may contribute to endothelial dysfunction, hypertension, and proteinuria in preeclampsia. J Clin Invest 2003;111:649-658.

6 Levine RJ, Maynard SE, Qian C, Lim KH, England LJ, Yu KF, Schisterman EF, Thadhani R, Sachs BP, Epstein FH, Sibai BM, Sukhatme VP, Karumanchi SA: Circulating angiogenic factors and the risk of preeclampsia. N Engl J Med 2004;350:672-683.

7 Weiler J, Tong S, Palmer KR: Is fetal growth restriction associated with a more severe maternal phenotype in the setting of early onset pre-eclampsia? A retrospective study. PLoS One 2011;6:e26937.

8 Signore C, Mills JL, Qian C, Yu K, Lam C, Epstein FH, Karumanchi SA, Levine RJ: Circulating angiogenic factors and placental abruption. Obstet Gynecol 2006;108:338-344.

9 Gómez-Arriaga PI, Herraiz I, López-Jiménez EA, Escribano D, Denk B, Galindo A: Uterine artery Doppler and sFlt-1/PlGF ratio: prognostic value in early-onset pre-eclampsia. Ultrasound Obstet Gynecol 2014;43:525-532.

10 Chaiworapongsa T, Romero R, Korzeniewski SJ, Cortez JM, Pappas A, Tarca AL, Chaemsaithong P, Dong Z, Yeo L, Hassan SS: Plasma concentrations of angiogenic/antiangiogenic factors have prognostic value in women presenting with suspected preeclampsia to the obstetrical triage area: a prospective study. J Matern Fetal Neonatal Med 2014;27:132144.

11 Redman CW, Sargent IL, Staff AC: IFPA Senior Award Lecture: making sense of pre-eclampsia - two placental causes of preeclampsia? Placenta 2014;35(suppl):S20-S25.
12 Roberts JM, Catov JM: Preeclampsia more than 1 disease: or is it? Hypertension 2008;51: 989-990.

13 Herraiz I, Dröge LA, Gómez-Montes E, Henrich W, Galindo A, Verlohren S: Characterization of the soluble fms-like tyrosine kinase- 1 to placental growth factor ratio in pregnancies complicated by fetal growth restriction. Obstet Gynecol 2014;124:265273.

14 Rana S, Schnettler WT, Powe C, Wenger J, Salahuddin S, Cerdeira AS, Verlohren S, Perschel FH, Arany Z, Lim KH, Thadhani R, Karumanchi SA: Clinical characterization and outcomes of preeclampsia with normal angiogenic profile. Hypertens Pregnancy 2013;32:189-201.

15 Redman CW, Staff AC: Preeclampsia, biomarkers, syncytiotrophoblast stress, and placental capacity. Am J Obstet Gynecol 2015; 213(4 suppl):S9.e1, S9-S11.

16 Menzies J, Magee LA, Macnab YC, Ansermino JM, Li J, Douglas MJ, Gruslin A, Kyle P, Lee SK, Moore MP, Moutquin JM, Smith GN, Walker JJ, Walley KR, Russell JA, von Dadelszen P: Current CHS and NHBPEP criteria for severe preeclampsia do not uniformly predict adverse maternal or perinatal outcomes. Hypertens Pregnancy 2007;26:447-462. 
17 American College of Obstetricians and Gynecologists; Task Force on Hypertension in Pregnancy: Hypertension in pregnancy. Report of the American College of Obstetricians and Gynecologists' Task Force on Hypertension in Pregnancy. Obstet Gynecol 2013;122: 1122-1131.

18 Tan MY, Koutoulas L, Wright D, Nicolaides $\mathrm{KH}$, Poon LC: A study protocol for the prospective validation study: Screening programme for pre-eclampsia (SPREE). Ultrasound Obstet Gynecol 2017, Epub ahead of print.

19 Cantwell R, Clutton-Brock T, Cooper G, Dawson A, Drife J, Garrod D, Harper A, Hulbert D, Lucas S, McClure J, Millward-Sadler H, Neilson J, Nelson-Piercy C, Norman J, O'Herlihy C, Oates M, Shakespeare J, de Swiet M, Williamson C, Beale V, Knight M, Lennox C, Miller A, Parmar D, Rogers J, Springett A: Saving mothers' lives: reviewing maternal deaths to make motherhood safer: 2006-2008. The Eighth Report of the Confidential Enquiries into Maternal Deaths in the United Kingdom. BJOG 2011;118(suppl 1):1203.

20 Shennan AH, Redman C, Cooper C, Milne F: Are most maternal deaths from pre-eclampsia avoidable? Lancet 2012;379:1686-1687.

21 Brown MA, Lindheimer MD, de Swiet M, van Assche A, Moutquin JM: The classification and diagnosis of the hypertensive disorders of pregnancy: statement from the International Society for the Study of Hypertension in Pregnancy (ISSHP). Hypertens Pregnancy 2001; 20:IX-XIV.

22 Zhang J, Klebanoff MA, Roberts JM: Prediction of adverse outcomes by common definitions of hypertension in pregnancy. Obstet Gynecol 2001;97:261-267.

23 Zeisler H, Llurba E, Chantraine F, Vatish M, Staff AC, Sennström M, Olovsson M, Brennecke SP, Stepan H, Allegranza D, Dilba P, Schoedl M, Hund M, Verlohren S: Predictive value of the sFlt-1:PlGF ratio in women with suspected preeclampsia. N Engl J Med 2016; 374:13-22.

24 Verlohren S, Llurba E, Chantraine F, Vatish M, Staff A, Sennström M, Olovsson M, Brennecke SP, Stepan H, Allegranza D, Schoedl M, Dilba P, Hund M, Zeisler H: The sFlt-1/PlGF ratio can rule out preeclampsia for up to four weeks in women with suspected preeclampsia (abstract). Pregnancy Hypertens 2016;6:140141.

25 Chappell LC, Duckworth S, Seed PT, Griffin M, Myers J, Mackillop L, Simpson N, Waugh J, Anumba D, Kenny LC, Redman CW, Shennan AH: Diagnostic accuracy of placental growth factor in women with suspected preeclampsia: a prospective multicenter study. Circulation 2013;128:2121-2131.
26 Verlohren S, Herraiz I, Lapaire O, Schlembach D, Zeisler H, Calda P, Sabria J, MarkfeldErol F, Galindo A, Schoofs K, Denk B, Stepan $\mathrm{H}$ : New gestational phase-specific cutoff values for the use of the soluble fms-like tyrosine kinase-1/placental growth factor ratio as a diagnostic test for preeclampsia. Hypertension 2014;63:346-352.

27 Verlohren S, Herraiz I, Lapaire O, Schlembach D, Moertl M, Zeisler H, Calda P, Holzgreve W, Galindo A, Engels T, Denk B, Stepan $\mathrm{H}$ : The sFlt-1/PlGF ratio in different types of hypertensive pregnancy disorders and its prognostic potential in preeclamptic patients. Am J Obstet Gynecol 2012;206:58.e1-e8.

28 Haddad B, Sibai BM: Expectant management in pregnancies with severe pre-eclampsia. Semin Perinatol 2009;33:143-151.

29 von Dadelszen P, Payne B, Li J: Prediction of adverse maternal outcomes in pre-eclampsia: development and validation of the fullPIERS model. Lancet 2011;377:219-227.

30 Schoofs K, Grittner U, Engels T, Pape J, Denk B, Henrich W, Verlohren S: The importance of repeated measurements of the sFlt-1/PlGF ratio for the prediction of preeclampsia and intrauterine growth restriction. J Perinat Med 2014;42:61-68.

31 Schaarschmidt W, Stepan H: The course of angiogenic factors in early- vs. late-onset preeclampsia and HELLP syndrome. J Perinat Med 2013:41:511-516.

32 Zeisler H, Llurba E, Chantraine F, Vatish M, Staff AC, Sennström M, Olovsson M, Brennecke SP, Stepan H, Allegranza D, Dinkel C, Schoedl M, Dilba P, Hund M, Verlohren S: Soluble fms-Like tyrosine kinase-1-to-placental growth factor ratio and time to delivery in women with suspected preeclampsia. $\mathrm{Ob}$ stet Gynecol 2016;128:261-269.

33 Rana S, Powe CE, Salahuddin S, Verlohren S, Perschel FH, Levine RJ, Lim KH, Wenger JB, Thadhani R, Karumanchi SA: Angiogenic factors and the risk of adverse outcomes in women with suspected preeclampsia. Circulation 2012;125:911-919.

34 Broekhuijsen K, van Baaren G, van Pampus MG, Ganzevoort W, Sikkema JM, Woiski MD, Oudijk MA, Bloemenkamp KWM, Scheepers HCS, Bremer HA, Rijnders RJP, van Loon AJ, Perquin DAM, Sporken JMJ, Papatsonis DNM, van Huizen ME, Vredevoogd CB, Brons JTJ, Kaplan M, van Kaam AH, Groen H, Porath MM, van den Berg PP, Mol BWJ, Franssen MTM, Langenveld J: Immediate delivery versus expectant monitoring for hypertensive disorders of pregnancy between 34 and 37 weeks of gestation (HYPITAT-II): an open-label, randomised controlled trial. Lancet 2015;385:2492-2501.
35 Koopmans CM, Bijlenga D, Groen H, Vijgen SM, Aarnoudse JG, Bekedam DJ, van den Berg PP, de Boer K, Burggraaff JM, Bloemenkamp KW, Drogtrop AP, Franx A, de Groot CJ, Huisjes AJ, Kwee A, van Loon AJ, Lub A, Papatsonis DN, van der Post JA, Roumen FJ, Scheepers HC, Willekes C, Mol BW, van Pampus MG: Induction of labour versus expectant monitoring for gestational hypertension or mild pre-eclampsia after 36 weeks' gestation (HYPITAT): a multicentre, openlabel randomised controlled trial. Lancet 2009;374:979-988.

36 Llurba E, Marsal G, Sanchez O, Dominguez C, Alijotas-Reig J, Carreras E, Cabero L: Angiogenic and antiangiogenic factors before and after resolution of maternal mirror syndrome. Ultrasound Obstet Gynecol 2012;40: 367-369.

37 Goa S, Mimura K, Kakigano A, Tomimatsu T, Kinugasa-Taniguchi Y, Endo M, Kanagawa T, Kimura T: Normalisation of angiogenic imbalance after intra-uterine transfusion for mirror syndrome caused by parvovirus B19. Fetal Diagn Ther 2013;34:176-179.

38 Hund M, Verhagen-Kamerbeek W, Reim M, Messinger D, van der Does R, Stepan H: Influence of the sFlt-1/PlGF ratio on clinical decision-making in women with suspected preeclampsia - the PreOS study protocol. Hypertens Pregnancy 2015;34:102-115.

39 Thadhani R, Kisner T, Hagmann H, Bossung V, Noack S, Schaarschmidt W, Jank A, Kribs A, Cornely OA, Kreyssig C, Hemphill L, Rigby AC, Khedkar S, Lindner TH, Mallmann P, Stepan H, Karumanchi SA, Benzing T: Pilot study of extracorporeal removal of soluble fms-like tyrosine kinase 1 in preeclampsia. Circulation 2011;124:940-950.

40 Thadhani R, Hagmann H, Schaarschmidt W, Roth B, Cingoez T, Karumanchi SA, Wenger J, Lucchesi KJ, Tamez H, Lindner T, Fridman A, Thome U, Kribs A, Danner M, Hamacher S, Mallmann P, Stepan H, Benzing T: Removal of soluble fms-like tyrosine kinase- 1 by dextran sulfate apheresis in preeclampsia. J Am Soc Nephrol 2016;27:903-913.

41 Brownfoot FC, Tong S, Hannan NJ, Binder NK, Walker SP, Cannon P, Hastie R, Onda K, Kaitu'u-Lino TJ: Effects of pravastatin on human placenta, endothelium, and women with severe preeclampsia. Hypertension 2015;66: 687-697.

42 Costantine MM, Cleary K: Pravastatin for the prevention of preeclampsia in high-risk pregnant women. Obstet Gynecol 2013;121:349353.

43 Stepan H, Herraiz I, Schlembach D, Verlohren S, Brennecke S, Chantraine F, Klein E, Lapaire O, Llurba E, Ramoni A, Vatish M, Wertaschnigg D, Galindo A: Implementation of the sFlt-1/PlGF ratio for prediction and diagnosis of pre-eclampsia in singleton pregnancy: implications for clinical practice. Ultrasound Obstet Gynecol 2015;45: 241-246. 
44 National Institute for Health and Care Excellence guideline DG 23 (2016): PlGF-based testing to help diagnose suspected pre-eclampsia (Triage PlGF test, Elecsys immunoassay sFlt-1/ PIGF ratio, DELFIA Xpress PIGF 1-2-3 test, and BRAHMS sFlt-1 Kryptor/BRAHMS PIGF plus Kryptor PE ratio). Available at https:// www.nice.org.uk/guidance/dg23/chapter/1recommendations (accessed January 2017).

45 Stepan H, Kuse-Föhl S, Klockenbusch W, Rath W, Schauf B, Walther T, Schlembach $\mathrm{D}$ : Diagnosis and treatment of hypertensive pregnancy disorders. Guideline of DGGG
(S1-Level, AWMF Registry No.015/018, December 2013). Geburtshilfe Frauenheilkd 2015;75:900-914.

46 Di Martino D, Cetin I, Frusca T, Ferrazzi E, Fuse F, Gervasi MT, Plebani M, Todros T: Italian Advisory Board: sFlt-1/PlGF ratio and preeclampsia, state of the art and developments in diagnostic, therapeutic and clinical management. Eur J Obstet Gynecol Reprod Biol 2016;206:70-73.

47 Hadker N, Garg S, Costanzo C, Miller JD, Foster T, van der Helm W, Creeden J: Financial impact of a novel pre-eclampsia diagnostic test versus standard practice: a decision-analytic modeling analysis from a UK healthcare payer perspective. J Med Econ 2010;13:728-737.

48 Schnettler W, Dukhovny D, Wenger J, Salahuddin S, Ralston RJ, Rana S: Cost and resource implications with serum angiogenic factor estimation in the triage of pre-eclampsia. BJOG 2013;120:1224-1232.

49 Vatish M, Strunz-McKendry T, Hund M, Allegranza D, Wolf C, Smare C: sFlt-1/PlGF ratio test for pre-eclampsia: an economic assessment for the UK. Ultrasound Obstet Gynecol 2016;48:765-771. 